\title{
CO2 capture on NiO supported imidazolium-based ionic liquid
}

\begin{abstract}
$\mathrm{CO} 2$ capture on $\mathrm{NiO}$ supported imidazolium-based ionic liquid, $\mathrm{NiO} /[\mathrm{emim}][\mathrm{HSO} 4] / \mathrm{SiO} 2$ as an adsorbent was investigated using gas adsorption analyzer and physicochemical properties of the adsorbent were characterized using X-ray powder diffraction (XRD), surface area analyzer (BET method) and temperature-program-desorption analysis (TPD). Immobilization of ionic liquid on silica, [emim][HSO4]/SiO2 slightly decreased the surface area compared to bare silica from 266 to $256 \mathrm{~m} 2 / \mathrm{g}$ due to the pore blocking by the confinement of IL in $\mathrm{SiO} 2$ pore. Interestingly, introduction of $\mathrm{NiO}$ on supported ionic liquid, $\mathrm{NiO} /[\mathrm{emim}][\mathrm{HSO} 4] / \mathrm{SiO} 2$ was increased the surface area as well as pore volume from 256 to $356 \mathrm{~m} 2 / \mathrm{g}$ and 0.14 to 0.38 $\mathrm{cm} 3 / \mathrm{g}$, respectively. The enhancement of surface area and pore volume was significantly increased the $\mathrm{CO} 2$ adsorption performance with capacity of $48.8 \mathrm{mg} \mathrm{CO} 2 / \mathrm{g}$ adsorbent compared to [emim][HSO4]/SiO2 $27.3 \mathrm{mg} \mathrm{CO} / \mathrm{g}$ adsorbent).
\end{abstract}

Keyword: Adsorption; CO2 capture; Desorption; Ionic liquid; Nickel oxide 